\title{
Um Estudo Fenomenológico Sobre a Vivência de Família em uma Comunidade Popular
}

A Phenomenological Study of the Family Experience in a Popular Community

Un Estudio Fenomenológico Sobre la Vivencia de Familia en una Comunidad Popular
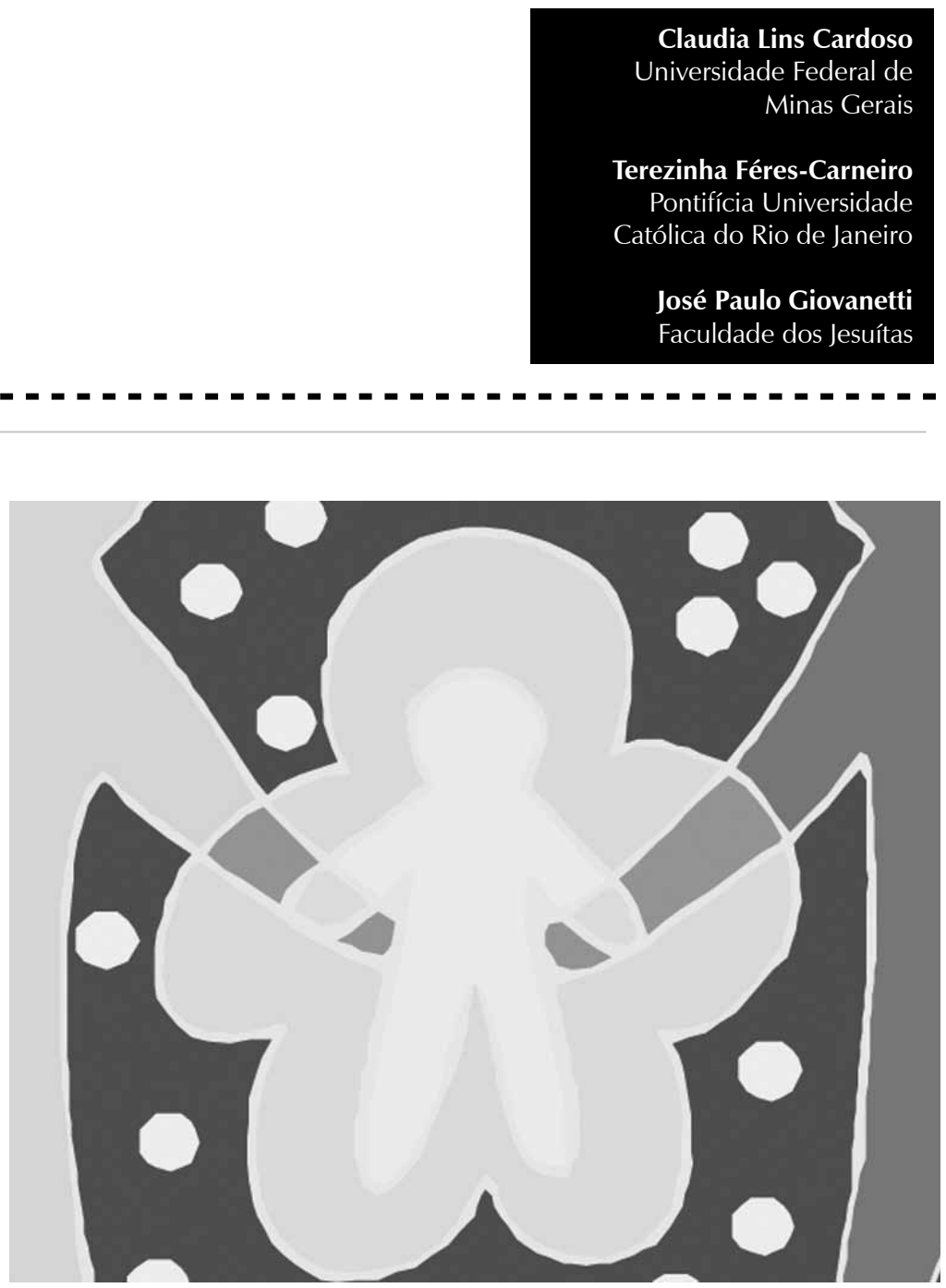
Resumo: O objetivo desta pesquisa foi investigar a vivência de família na perspectiva de três moradores de uma comunidade popular de Belo Horizonte (MG). A vivência foi concebida como a ressonância na subjetividade da pessoa, ocorrida a partir da interação entre a consciência e a realidade. Foi utilizado o método fenomenológico de pesquisa. A análise dos dados apontou os seguintes temas representativos revelados nos depoimentos: concepção de família, papéis na dinâmica familiar, elementos que desestruturam a família, problemas enfrentados pela família, a percepção das famílias da comunidade e a vivência do trabalho com as famílias da comunidade. A família como base para a vida, o diálogo, a afetividade, a religião, a presença e a importância da rede familiar e da figura paterna foram as unidades de significado comuns nos depoimentos. Como conclusão, foi enfatizado o mérito do estudo da vivência da família para o desenvolvimento de projetos de assistência psicológica à comunidade.

Palavras-chave: Família. Comunidade. Vivência. Fenomenologia.

Abstract: The purpose of this study was to examine the family experience from the perspective of three residents of a popular community in Belo Horizonte (MG). The experience was conceived as the resonance in the person's subjectivity occurred due to the interaction between conscience and reality. The phenomenological research method was used. The analysis of the data allowed the following representative subjects revealed in the statements: conception of family, roles in family dynamics, the unstable elements in the family, problems faced by the family, perception of the community's families and work experience of the community's families. The family as the base of life, dialogue, affection, religion and the presence and the importance of the family network and of the paternal figure were the units of common meaning revealed by the statements. In conclusion, the merit of the family experience study was emphasized for the development of projects of psychological assistance for the community.

Keywords: Family. Community. Life experience. Phenomenology.

Resumen: El objetivo de esta pesquisa fue investigar la vivencia de familia en la perspectiva de tres habitantes de una comunidad popular de Belo Horizonte (MG). La vivencia fue concebida como la resonancia en la subjetividad de la persona, ocurrida desde la interacción entre la conciencia y la realidad. Fue utilizado el método fenomenológico de pesquisa. El análisis de los datos señaló los siguientes temas representativos revelados en las declaraciones: concepción de familia, papeles en la dinámica familiar, elementos que desestructuran la familia, problemas enfrentados por la familia, la percepción de las familias de la comunidad y la vivencia del trabajo con las familias de la comunidad. La familia como base para la vida, el diálogo, la afectividad, la religión, la presencia y la importancia de la red familiar y de la figura paterna fueron las unidades de significado comunes en las declaraciones. Como conclusión, fue enfatizado el mérito del estudio de la vivencia de la familia para el desarrollo de proyectos de asistencia psicológica a la comunidad. Palabras clave: Familia. Comunidad. Vivencia. Fenomenología.

Por ser o Brasil um país onde a maioria da população é pobre, torna-se fundamental que o segmento popular seja privilegiado no desenvolvimento de estudos, pois há diferenças significativas entre suas particularidades e as dos segmentos médio e alto. A linha de pobreza é estabelecida em meio salário mínimo de renda familiar mensal per capita, e a linha de indigência, em $1 / 4$ do salário mínimo de renda familiar mensal per capita. Em geral, as comunidades populares são vinculadas essencialmente à falta de recursos financeiros, e isso repercute em outras dimensões que extrapolam essa esfera.

A vida das pessoas moradoras nessas comunidades caracteriza-se pela presença de vários fatores estressores (apesar de nem todos serem exclusivos desse segmento social) muitas vezes concomitantes, como, por exemplo, desemprego, dependência de álcool e drogas, envolvimento com o tráfico e com o crime organizado, fome, abuso sexual, violência domiciliar e comunitária, mortes precoces, precariedade de moradia, ausência de saneamento básico e a inexistência ou ineficiência do serviço público, que muitas vezes não atende nem minimamente as suas necessidades. Soma-se a tudo isso as especificidades étnicas, culturais, regionais e religiosas, que causam impacto tanto na concepção de família quanto na sua estrutura, na dinâmica e nos aspectos mais cotidianos de sua existência. Há também o preconceito que uma parte da sociedade em geral tem dessas comunidades, daí a intolerância, as desqualificações e os outros prejuízos. 
Gomes (1988) pesquisou famílias de uma comunidade carente da periferia de São Paulo e evidenciou aspectos constantemente presentes na experiência familiar das pessoas entrevistadas: a família era, como ponto de partida, constituída em função de um fator afetivo (por exemplo, um vínculo de criação ou de apadrinhamento), e não necessariamente do laço consangüíneo; havia uma hierarquia que orientava as relações interpessoais de acordo com o critério mandar/obedecer, fosse do homem em relação à mulher, fosse dos mais velhos em relação aos mais novos; observou-se também a existência de formas veladas e explícitas de burlar as regras vigentes no grupo familiar, a atribuição ao homem da responsabilidade pelo provimento das necessidades materiais, e, à mulher, cabia o cuidado com o bem-estar físico e afetivo dos filhos e o vínculo afetivo mais intenso entre a mãe e os filhos, sendo que, em caso de separação, era a mulher quem passava a assumir a responsabilidade pelas crianças. Além disso, a família geralmente estava diretamente envolvida ou sofria intervenções de outros sistemas ou instituições de proteção ou assistência: escola, judiciário, ONGs, igrejas, Estado, etc. Resultados semelhantes foram encontrados nos estudos realizados por Cardoso e Féres-Carneiro (2008), Oliveira e Bastos (2000), Saleh (2001) e Sarti (2003a, 2003b).

Mello (2002) ressalta a importância dos laços das famílias moradoras em uma comunidade popular da periferia de São Paulo ao distinguir pelo menos três tipos de laços: a família nuclear própria (constituída por pai, mãe e filhos), a família composta por várias famílias nucleares que moram juntas por questão de sobrevivência (pais, filhos, avós, sobrinhos, etc) e a família que inclui pessoas sem laços consangüíneos (apadrinhamento ou outros tipos de alianças). Essa diversidade de arranjos leva a autora a ratificar o polimorfismo familiar como alternativa de organização (em oposição à noção de que se trata de famílias "desorganizadas").

Sarti pesquisou o modo particular de construção da noção de família como uma ordem moral entre famílias pobres da periferia de São Paulo, e revelou a existência das seguintes características: configuração em rede (em oposição à concepção de constituição em núcleo composto por pai, mãe e filhos); distinção entre "casa", cuja responsabilidade ficaria a cargo da mulher, e "família", que seria da responsabilidade do homem, constituindo um par complementar, mas hierárquico; a não-desvinculação da família de origem a partir do casamento, especialmente em função das obrigações familiares que se mantém; o ciclo de desenvolvimento da vida familiar com rupturas freqüentes, principalmente na fase de criação dos filhos, devido à instabilidade típica da vida desse segmento da população; o grande número de famílias chefiadas por mulheres; o vínculo mais forte entre pais e filhos e, finalmente, a circulação da criança pela rede social na qual a família está envolvida. A família possui uma importância central para os pobres, por constituir rede de apoio ou de ajuda mútua em função da sua condição de desamparo social.

Em trabalho posterior, a autora ressalta que a noção de família entre os pobres se dá em torno de um eixo moral, de acordo com critérios de obrigações recíprocas, sobrepondo-se às relações de parentesco e de consangüinidade. Assim, "são da família aqueles com quem se pode contar, quer dizer, aqueles em quem se pode confiar" (Sarti, 2003a, p. 33, grifos da autora).

Cardoso e Féres-Carneiro (2008) verificaram que as pessoas têm a família como uma referência fundamental na vida, no sentido de experiência de felicidade, suporte e promoção de equilíbrio pessoal. Entretanto, ela também foi associada a experiências de 
A vivência é pré-reflexiva,

no sentido de ser anterior

a qualquer elaboração

racional, e sua importância

reside no fato

de ser uma

referência

fundamental na

orientação da

vida (Amatuzzi,

1996, 2001a,

2001 b; Forghieri,

1993; Valle, 1998; Vaz, 1986).

\footnotetext{
${ }^{1}$ Os nomes são fictícios para preservar a identidade dos sujeitos que assinaram o Termos de Consentimento Livre e Esclarecido.
}

conflitos entre os membros, preocupações, solidão e sofrimento. A importância do diálogo entre pais e filhos e a experiência religiosa foram outros aspectos ressaltados. As autoras destacaram a ênfase dada pelas pessoas da comunidade de baixa renda à perspectiva interpessoal da dinâmica familiar, tanto no que diz respeito às expectativas e às idealizações quanto às dificuldades de relacionamento. Não houve menção a sofrimentos por não possuírem uma configuração familiar idealizada (composta por pai, mãe e filhos), mas a experiências do seu cotidiano (brigas, abandono, alcoolismo, violência, etc.). Também foram descritas situações nas quais a postura individualista de algum membro acarretava conflitos e solidão.

Quanto à importância da participação da mulher para a provisão financeira em famílias que vivem em situações de pobreza em Belo Horizonte, Oliveira (2005) constatou que o homem é o provedor principal em apenas $23,7 \%$ das famílias, ao passo que a mulher provedora representa $74,5 \%$. Esses dados apontam uma inversão dos papéis no que se refere ao sustento econômico, mostrando que, nas famílias pobres, a mulher substituiu o homem na posição de principal arrimo financeiro. Os homens desse segmento social vêm sofrendo uma redução das suas oportunidades de inserção no mercado de trabalho, o que aumenta, portanto, os níveis de desemprego e de subempregos. Já a mulher obteve essa ampliação no mercado em função das oportunidades de emprego doméstico. Essa reversão de papéis parece se refletir também em outro índice trágico: o aumento da violência doméstica. Considerando-se que a função de provedor legitima uma posição de dominação sobre os demais membros da família, à medida que o homem perde essa condição, ele responde com atos de violência intrafamiliar.

Em outra investigação realizada na capital mineira, Vasconcelos (1999) reconheceu as conseqüências da pobreza na infância. Como o espaço entre as casas é mínimo e os becos são contaminados por lixos e esgotos, as brincadeiras das crianças ficam reduzidas e marcadas pela falta de espaço. Por sua vez, várias mães mantêm os filhos trancados em casa, como tentativa de protegê-los dos perigos ao redor. Com isso, a possibilidade de brincar fica restrita aos cômodos da casa (muitas vezes único e minúsculo, quando se trata de um barraco construído com material inadequado). Com essa falta de espaço e a abundante energia das crianças, é comum que as brincadeiras acabem tirando o sossego dos adultos, o que provoca atritos na família e torna as crianças contidas ou agressivas. Mas o autor revela também o encurtamento da infância pelo trabalho precoce, seja em casa, ajudando na criação dos irmãos mais novos e assumindo a responsabilidade pelas atividades domésticas, seja na rua, fazendo biscates para colaborar com a renda familiar.

Com o objetivo de investigar a vivência de família a partir da perspectiva de pessoas moradoras de comunidade popular de Belo Horizonte (MG), foi desenvolvida a pesquisa que será apresentada a seguir. Por vivência, compreendeu-se a ressonância ou o impacto que se dá na subjetividade da pessoa em conseqüência da interação entre a consciência e a realidade. A vivência é préreflexiva, no sentido de ser anterior a qualquer elaboração racional, e sua importância reside no fato de ser uma referência fundamental na orientação da vida (Amatuzzi, 1996, 2001a, 2001b; Forghieri, 1993; Valle, 1998; Vaz, 1986).

\section{Metodologia}

\section{Sujeitos $^{1}$}

A escolha dos sujeitos ocorreu de acordo com o procedimento da amostragem intencional, proposto por Thiollent (2000), segundo o qual os sujeitos são escolhidos por demonstrarem 
maiores chances de abordar o tema que se quer investigar, seja a partir de contatos anteriores com o pesquisador, seja pela indicação de terceiros.

Foram convidadas para participar da pesquisa três pessoas que realizavam regularmente algum tipo de assistência às famílias do Conjunto Santa Maria, bairro popular de Belo Horizonte (MG), local onde moravam a Sra. Tânia (T), 40 anos, a Sra. Aparecida (Ap.), 55 anos, e o Sr. Adão (Ad.), 45 anos. Todos eram casados, com filhos (primeira união), moravam em casa própria e eram católicos.

O Conjunto Santa Maria se compõe de residências simples, com escritura e registro na Prefeitura. Ele é cercado por várias favelas, em que a maioria das habitações foi construída em decorrência de invasão, de forma precária e com materiais inadequados; as ruas não são asfaltadas, há muitos becos, e os moradores não pagam impostos.

\section{Coleta e análise dos dados}

Os procedimentos de coleta e de análise dos dados foram operacionalizados com base naqueles propostos na literatura sobre pesquisa fenomenológica (Amatuzzi, 2001a, 2001b; Forghieri, 1993; Giorgi, 1985; Moreira, 2002).

Foram realizadas entrevistas individuais semi-estruturadas, gravadas e com duração aproximada de uma hora. Na transcrição, mantiveram-se as falas em sua forma literal, buscando-se, com isso, preservar a expressão das pessoas o mais fielmente possível. A questão inicial foi: "Gostaria de começar nossa entrevista pedindo que o(a) senhor(a) se apresentasse e também a sua família, da forma que quiser." Ela teve como objetivo propiciar ao entrevistado uma reflexão inicial sobre sua história familiar e suas vivências, com a plena liberdade de escolher o(s) aspecto(s) por onde gostaria de começar.
Depois da transcrição, cada entrevista foi submetida aos seguintes procedimentos de análise fenomenológica: leitura dos depoimentos para obtenção de uma visão global, divisão em unidades de significado, interpretação dos dados, comparação entre os dados levantados para cada sujeito e síntese dos resultados.

A análise dos depoimentos, em consonância com o método fenomenológico de pesquisa, privilegiou os elementos reveladores da vivência de família expressos nos depoimentos. Após inúmeras leituras, os conteúdos expressos nas entrevistas foram agrupados em unidades temáticas, compostas pelas unidades de significado que revelam as vivências das pessoas entrevistadas. Assim, todas as frases que apresentaram elemento constituinte da vivência de família foram destacadas e numeradas. Em um momento posterior, elas foram reagrupadas de acordo com o tema pertinente representativo da vivência de família.

A partir da análise dos depoimentos, foram encontrados os seguintes temas representativos da vivência de família: 1) a concepção de família: definição, configuração familiar, elementos estruturantes e posturas que organizam a família; 2) os papéis na dinâmica familiar: o arrimo, a rede familiar, o pai e a esposa; 3) os elementos desintegradores da família: falta de união entre o casal, o individualismo, falta de diálogo, falta de escuta e falta de cumplicidade e de comunhão; 4) os problemas enfrentados pela família: conflitos entre os membros, falta de união entre os membros do casal, falta de escuta e de diálogo; 5) a percepção das famílias da comunidade: individualismo, falta de diálogo, falta de cumplicidade e falta de comunhão; 6) a vivência do trabalho com as famílias da comunidade. 


\section{Discussão dos depoimentos: em busca da expressão da vivência}

Os depoimentos evidenciaram a riqueza de elementos que fundam a vivência de família das pessoas entrevistadas. No cotidiano, eles se integram de modo dinâmico e compõem o viés singular com que cada pessoa concebe sua família e se coloca em relação a ela. Nesse sentido, as pessoas descreveram a importância da família na sua vida:

...Família, pra mim, tá dentro de tudo e tudo tá dentro da família... (T)

...Família é um grupo de pessoas que têm afinidades, e que... onde as pessoas se desenvolvem, crescem e que trocam experiências. (Ad.)

...Porque uma coisa que eu vejo em muitas famílias é esse movimento, assim, de estrutura mesmo. Porque se a gente tem uma base para criar os filhos, os filhos acabam conseguindo os objetivos na vida e sendo bons cidadãos, sem pertencer ao caminho que não deve, que é esse caminho da droga, da perdição, da prostituição que a gente sempre vê. (Ap.)

...Proteção é isso: quando um tá fragilizado, tá com problema, eu acho que o refúgio é sempre a família, é sempre NA família. (Ad.)

A análise fenomenológica dos depoimentos permitiu a apreensão da família vivenciada como a base para a vida de todas as pessoas de duas formas: na sua presença em quase todas as situações pessoais e como o grupo que oferece o suporte diante das adversidades. Para todos os entrevistados, ela é a estrutura, a fortaleza, o refúgio. Tudo passa por ela e ela passa por tudo. Além de ser o núcleo no qual a pessoa se constitui enquanto ser-no-mundo, onde se desenvolvem os afetos, os valores, a cultura e as demais referências da vida, a família dá continência e um sentimento de pertencimento aos seus membros. É um grupo composto por pessoas diferentes, protetor e gerador de crescimento, não importando a sua configuração (se nuclear ou extensa) nem a existência de consangüinidade. Os relacionamentos ali estabelecidos são relevantes, devem ser estáveis (presença), promotores de interação (através do diálogo) e de vivências afetivas, que, juntamente ao sustento da fé, oferecem o suporte necessário ao crescimento pessoal e ao enfrentamento das vicissitudes. Isso é muito importante, pois a não-ocorrência de tal continência na vida de um indivíduo gera graves transtornos de diversas naturezas.

“Eu não acho que a família resume só em tipo pai, mãe e filhos, não... Eu acho que a família é tudo isso, é quem te quer bem" (Ap.). “... Pode ser com laço de sangue ou não" (Ad.).

A família não é vivenciada como um grupo qualquer, e sim, como aquele que oferece um sentimento de pertencimento e que propicia crescimento, não necessariamente vinculado a laços de sangue. Não há menção a nenhuma configuração de padrão de família, nem aquela composta por pai, mãe e filhos. Isso se mostra, por exemplo, nos depoimentos do Sr. Adão, quando ele diz não ter contato com os irmãos de sangue, relacionamento que não é, portanto, vivenciado como família, enquanto com os irmãos adotivos, sim. Mesmo a Sra. Tânia, que se refere ao modelo tradicional de configuração familiar, descreve toda a sua vivência em termos de família extensa.

A função formadora da subjetividade do indivíduo e, em conseqüência, da sociedade, pode ser ilustrada na afirmação de Sarti (2003b), segundo a qual a família é "uma referência simbólica fundamental que permite pensar, organizar e dar sentido ao mundo social dentro e fora do âmbito familiar" (p. 9). Entretanto, ela ressalta que a noção de família é construída em torno de um eixo moral constituído por critérios de obrigações recíprocas, que levam a considerar "da família" aqueles com quem se pode contar. Isso também foi percebido no trabalho de campo descrito por Cardoso e Féres- 
Carneiro (2008), no qual as pessoas disseram que muitas vezes os vizinhos "são mais da família do que os de sangue", justamente porque contribuem de alguma maneira com o cotidiano familiar. Assim, a vivência do arranjo familiar também se coaduna com os resultados encontrados por Saleh (2001) sobre os critérios de pertencimento familiar das famílias de baixa renda que estudou, a saber: qualidade de convivência, grau e disponibilidade para ajudar, família de origem e fatores afetivos.

Acho que toda família tem que ter esse cuidado: pode ser uma horinha sentadinho no colo, um abracinho assim. (Ap.)

Ah, o que está mais presente é amor. Muito, muito mesmo! Amor, assim, de mãe para o filho, de filho pra com a mãe, de marido pra com mulher, de cachorro pra com os meninos, de cachorro pra comigo, de tudo, sabe? (T)

Da afetividade, fica por conta dela. Até porque eu tenho pouco tempo. (Ad.)

Quanto aos elementos constituintes da família, referentes àquilo que sustenta a forma como ela é vivenciada e que servirá como diretriz ao posicionamento pessoal diante do mundo, foi possível captar uma rica diversidade na intencionalidade expressa nos depoimentos dos entrevistados. A afetividade, o diálogo, a presença e a religião foram os elementos que proporcionam estrutura, comuns na vivência de família das pessoas entrevistadas.

Todos os entrevistados revelaram a afetividade como um elemento que dá estrutura à vivência de família e, em conseqüência, como fundamento importante para considerar quem a constitui. Ela é descrita como marca que se carrega por toda a vida e que é promotora da força necessária para a superação das adversidades, nas suas várias formas de expressão: no amor, no carinho, na alegria, na atenção, no cuidado, na presença e na saudade dos familiares distantes ou falecidos. A compreensão dos depoimentos aponta a afetividade como uma força capaz de promover a transformação pessoal; portanto, a família constitui um espaço fundamental para a demonstração dos afetos, e há conseqüências nefastas para seus membros nas situações em que, por qualquer motivo, eles não podem ser expressos.

\begin{abstract}
...A coisa começou a dar certo e tem dado certo por causa disso, por causa do diálogo, da coisa da gente sentar e conversar mesmo. (T)

Acho que vai muito da mãe, de ter essa força de superar tudo ao redor, de ter paciência mesmo se, apesar do marido, de, em vez de briga, de diálogo, de ter sempre o diálogo, porque não adianta brigar, gritar, mas conversar naquele momento, não que a pessoa tá nervosa. (Ap.)
\end{abstract}

O diálogo é vivenciado como um elemento fundamental para o bom funcionamento da dinâmica familiar, na medida em que ele permite a valorização das diversas perspectivas de seus componentes, proporciona a abertura para o novo e gera o consenso, aproximando as pessoas e facilitando, com isso, a resolução de conflitos. Nesse sentido, ele é considerado um fator imprescindível na melhoria da qualidade das relações familiares bem como no fortalecimento de seu vínculo. Trata-se de uma força transformadora, conciliadora e promotora da flexibilização de posturas na família, aumentando o seu grau de interação. Todos os participantes da pesquisa apontam a mãe como a responsável pela instauração do diálogo com os filhos. Ele é tão importante, que sua falta é considerada um dos elementos desencadeadores da desestrutura na família.

A importância do diálogo na dinâmica familiar também foi verificada por Cardoso e FéresCarneiro (2008). Todavia, uma investigação mais detalhada revelou que o que as pessoas participantes do estudo chamavam de diálogo era um tipo de comunicação por meio da qual os pais falavam e os filhos obedeciam, o que 
era fonte de conflitos e tensões familiares de diversas naturezas.

...A gente tem um momento mais difícil, mas tem esse momento bom, de quando a gente tá presente, quando a gente pode encontrar... (Ap.)

...Tem sempre um que é o arrimo, aquele ali é que segura toda a onda... (T)

Ontem mesmo, conversei com uma mãe que tem três filhos e que não têm pai, e ela falou assim: "Eu sou pai e mãe". Aí eu falei: "Você não pode ser pai e mãe, não! Você pode ser uma boa mãe pra um filho". Pro filho, o pai faz falta. E eu acho que a figura masculina faz falta. (Ad.)

A presença é outro elemento vivenciado como parte constituinte da família, especialmente as presenças do pai, da mãe e da rede familiar, como garantias para a base dada aos filhos. Porém, além dessas, a Sra. Tânia enfatiza a presença do arrimo: aquele que ajuda a enfrentar as dificuldades de todos os membros da família ao assumir a responsabilidade de amparar a família (não necessariamente no aspecto financeiro) como importante no sistema familiar.

A questão da presença paterna é um dos temas relevantes do depoimento do Sr. Adão. Ele até reconhece a importância da presença da mãe para o desenvolvimento dos filhos, mas sua fala se alterna entre salientar enfaticamente a importância da presença do pai na vida dos filhos e expressar a sua preocupação em relação à sua falta de tempo para com os filhos e aos eventuais prejuízos que isso poderia causar ao seu desenvolvimento. Apesar dessa exigência da presença paterna, ele revela conflitos pela falta de tempo para estar com os filhos, em decorrência do excesso de trabalho. Vale lembrar que ele destaca a importância da figura paterna em um contexto no qual é muito comum a ausência do pai na criação dos filhos.

A literatura mostra que, em boa parte das famílias de baixa renda, cabe à mulher (seja a mãe, a avó ou qualquer outra figura feminina) o papel de apoio às diversas situações familiares (mesmo naquelas onde o homem é o provedor), ainda que ela não receba a conotação explícita de arrimo. Isso se torna evidente, por exemplo, nas situações de gravidez precoce, especialmente quando o pai não assume a paternidade e deixa a criação dos netos a cargo das avós (Saleh, 2001), ou, então, em casos de viuvez ou de separação, quando, em geral, a mãe acaba acolhendo os familiares em questão (Sarti, 2003b). Não foi encontrada na literatura nenhuma referência específica ao arrimo, mas o modo como ele é apresentado na pesquisa se aproxima daquele definido por Silveira (2007) na sua descrição sobre o cuidador familiar:

\footnotetext{
...Primeiro a gente tem que ter a religião, a gente tem que ter obediência, a gente tem que ter muita fé em Deus... (Ap.)

...E o que que fizemos nesse momento, a família toda? Juntou todo mundo nesse momento, ajoelhou, e reza, reza, reza... (T) Não é só as pessoas falar: "Ó, é Deus que falou..." Não! Tem que trazer pra hoje, o bicho tá pegando hoje, tem que trazer pra estas questões... (Ad.)
}

A religião é vivenciada como uma raiz importante, como mantenedora da família, como sustento nas situações difíceis, como protetora e como doadora de esperança de dias melhores. Entretanto, o Sr. Adão, além de vivenciar a religião como um elemento que dá apoio à família, atribui-lhe outro sentido: o do componente social implícito nessa vivência. Ele afirma que, quando a religião aborda apenas os aspectos espirituais, sem integrar as questões sociais da comunidade, não promove transformações, e, por isso, cai no vazio. Os depoimentos denotam, então, Deus e a religião como promotores de um sentido de vida para a família e como o princípio organizador de tudo, pois dão o sustento e a referência para o caminho a ser seguido.

O estudo de Saleh (2001) também confirmou a religião como suporte para enfrentar 
as dificuldades. Entretanto, não foram encontrados na literatura estudos que abordassem o papel social da religião nas comunidades de classe popular.

Então, era assim, era aquela família onde o pai mandava. (T)

Na questão da criação dos meninos, aí, sim. Eu deixo pra ela (a mãe) ficar mais com essa parte. (Ad.)

Então, eu acho que, pra ter essa estrutura, pelo menos a mãe - é claro que o pai também tem que estar - mas mais é a mãe que sempre tem que estar ali presente. Eu falo mesmo, que mãe é mãe, e é uma heroína mesmo. (Ap.)

O papel do pai na família foi um tema comum a todos os depoimentos, apesar da descrição de vivências distintas. Porém, há várias situações em que ele é apreendido como uma figura ausente ou autoritária. Para o Sr. Adão, único participante masculino da pesquisa, o pai é uma referência insubstituível no desenvolvimento dos filhos, além de ser o responsável pelo trabalho pesado fora de casa. Também é função paterna a aplicação de regras e limites para os filhos, o que ele afirma nem sempre acontecer por meio do diálogo, mas mediante uma postura impositiva. Ele demonstra uma atitude autoritária até mesmo em relação à esposa, no exercício de suas atribuições maternas, e toma para si a responsabilidade de cobrar dela o desempenho de suas funções, como, por exemplo, no acompanhamento escolar ou no lazer dos filhos, apesar de assumir também a função de apoiá-la e de dividir com ela as responsabilidades e as dificuldades do cotidiano da família

Esses resultados se coadunam com aqueles encontrados por Sarti (2003b) quanto à divisão de papéis nas famílias pobres. Ao estabelecer princípios definidores de determinados aspectos da dinâmica familiar e da hierarquia homem/mulher, com as respectivas autoridades e responsabilidades atribuídas a cada um, a autora evidencia que são delegados ao homem o papel de chefe da família e a responsabilidade pelo sustento e pela honra, aspectos importantes na composição da autoridade paterna. CabeIhe também a função de ser o intermediário entre a família e o mundo externo, pois a sua presença é uma garantia de respeitabilidade familiar. A autora sustenta ainda que, mesmo nas situações nas quais ele não oferece os recursos financeiros necessários à sobrevivência da família, sua presença continua importante como autoridade moral perante os outros.

Também Saleh ressalta que, apesar de ser comum o pouco tempo de permanência dos homens nas famílias das comunidades de baixa renda (evidenciado pelo grande número de famílias monoparentais femininas), a figura masculina faz falta como modelo para os filhos. Isso facilita a sua identificação com outros homens da comunidade, incluindo aqueles ligados ao tráfico de drogas e ao crime, o que eleva os índices de violência.

\begin{abstract}
...Mas o companheiro acaba - a palavra é essa mesma - sugando o suor delas... (Ap.) Se eu for te falar o que está dentro do coração, de verdade... eu não acho que marido é família não, sabe? Porque tem muitas famílias que não têm marido ou até já teve e às vezes são muito mais estruturadas e mais felizes de que essas que têm marido. (Ap.)

Eu acho que eu fui mais apoio dela mesmo (da esposa) do que outra coisa, até. (Ad.) Até hoje, se tem alguma coisa que não está dando certo, é meu. Se deu certo, puxou a ele. (Ap)
\end{abstract}

Por outro lado, as vivências dos entrevistados sobre a figura masculina foram contraditórias quanto às funções de pai e de marido. O Sr. Adão enfatiza, ao longo de toda a entrevista, a importância da presença do pai para o bom desenvolvimento dos filhos. Porém, ao mencionar o homem no papel de pai, a Sra. Aparecida afirma ser a sua presença positiva e necessária, semelhante ao sentido dado pelo Sr. Adão; todavia, o seu discurso muda quando faz alusão ao homem no papel de marido. 
Quanto à função de marido, a Sra. Tânia a menciona de maneira positiva, apesar de um período de grave crise conjugal. Já a Sra. Aparecida revela vivências de falta de companheirismo, desqualificação e outras de natureza negativa em relação ao cônjuge, desconsiderando-o inclusive como parte da família. Por sua vez, o Sr. Adão fez uma única referência a si mesmo na função de marido. Foram descritas mais situações nas quais o homem e a mulher desempenhavam as funções paterna e materna do que aquelas em que eles exerciam suas funções conjugais. Com exceção do depoimento da Sra. Tânia, os outros ratificaram a posição de alguns autores em que, nas famílias de baixa renda e nas moradoras de comunidade popular, o vínculo é mais forte entre pais e filhos do que entre marido e esposa (Cardoso \& FéresCarneiro, 2008; Saleh, 2001; Sarti, 2003b).

Aí, eu cobro dela: 'Tá olhando os cadernos dos meninos?' Ta. (Ad.)

...Porque o que a gente vê muito nas famílias é aquele homem que chega e que quer achar tudo pronto, tudo do jeito, que o menino não pode subir na cama, não pode subir no sofá, entendeu? (Ap.)

Quanto à divisão das funções familiares, Sarti propõe que, em uma posição complementar ao homem, compete à mulher o papel de chefe da casa, cujas principais responsabilidades são a manutenção da união familiar e os cuidados com a casa e com a família (como mãe e como dona-de-casa). Nesse sentido, a maternidade confere uma autoridade especial, sendo valorizada a sua importância no âmbito familiar, perspectiva essa também compartilhada por Saleh (2001).

Os resultados da presente pesquisa expressam vivências nessa direção. Todos os entrevistados apresentam a mulher como a responsável pelos cuidados com a casa e com os filhos (mesmo aquelas que têm emprego). O Sr. Adão, por exemplo, assume seu papel de provedor e confirma a função de chefe da casa atribuída à esposa no que concerne à criação dos filhos. A Sra. Aparecida, por outro lado, declara que, mesmo nos momentos em que o marido esteve desempregado, ele não colaborava nas tarefas cotidianas com as crianças. Já a Sra. Tânia descreve o marido como o provedor da casa (chefe da família) e revela a função da mulher como a de cuidadora das relações familiares (mediante a instauração do diálogo, da afetividade e o desempenho da função de arrimo da família, por exemplo).

...Porque geralmente, quando a gente casa, o tempo da gente é muito pouco pra gente dar conta de trabalhar, de cuidar de casa, de cuidar de criança.... (Ap.)

Meus meninos, agora, a questão de escola, quem fiscaliza os cadernos é ela (a mulher) que faz. (Ad.)

(Em relação à responsabilidade pelo sustento da família) Ela (a mulher) trabalha também. (Ad.)

Na questão da criação dos meninos, aí, sim. Eu deixo pra ela (a mulher) ficar mais com essa parte. (Ad.)

Entretanto, apesar dessa divisão de papéis, os depoimentos revelam uma sobrecarga da mulher, que, além de suas atribuições como mãe e dona-de-casa, muitas vezes também tem como dever a provisão de, pelo menos, parte do dinheiro para a subsistência da família.

Tal fato se aproxima dos dados encontrados por Oliveira (2005), em seu estudo sobre a provisão das famílias de baixa renda, em Belo Horizonte. Seus resultados demonstram que, na maioria dos domicílios da capital mineira desse segmento socioeconômico, a mulher ou é a principal responsável pelo sustento financeiro da família ou é co-provedora, contribuindo com 40 a $60 \%$ da renda familiar. Resultados semelhantes foram obtidos por Saleh (2001).

...O sobrinho já é meu desde pequeno, que mãe dele viajava muito pra trabalho ...ela não tinha como cuidar. (T)

Foi um período bem difícil pra mim, porque 
assim, eu vim da roça direto e minha tia trabalhava fora também, e eu ficava com as minhas primas e estudava à noite, né? (Ap.) Na verdade ela (a esposa) não teve família. Ela foi criada pela avó, a mãe dela era falecida, teve um pai que até conheceu, mas tinha outras famílias, mas... (Ad.)

A rede familiar é outra unidade temática presente no depoimento das três pessoas entrevistadas. Nenhuma delas teve o vínculo com a família de origem rompido ou atenuado, a partir do casamento. Nesse sentido, a família extensa (rede) é vivenciada como aquela que acolhe e auxilia os diversos núcleos familiares em situações de necessidade, como, por exemplo, na criação, permanente ou temporária, das crianças diante da impossibilidade de seus pais o fazerem ou nas dificuldades financeiras. Todas as pessoas entrevistadas descrevem alguma situação em que pelo menos um parente da família extensa prestou assistência em uma adversidade.

Essa rede se mantém, principalmente, pelo fato de se tratar de famílias com carências de diversas naturezas e com a probabilidade de vários rompimentos no ciclo de vida familiar (mortes precoces pelo envolvimento com o tráfico ou com o crime organizado, separações causadas pelas precárias condições de vida, circulação das crianças na família diante da impossibilidade dos pais para criá-las, etc.). Assim sendo, a rede familiar funciona como um suporte, com o qual se pode contar nas mais variadas necessidades (Oliveira, 2005; Saleh, 2001; Sarti, 2003b, Szymanski, 2002).

Quanto aos elementos constituintes da vivência de família, sem os quais a mesma não pode ser pensada, destaca-se o caráter relacional captado na análise fenomenológica das entrevistas. Dos quatro elementos comuns aos três depoimentos, apenas um não possui essa ênfase (religião, Deus). Assim, além do diálogo, da afetividade e da presença, a proteção, o apoio, a comunhão e a valorização das diferenças entre os familiares foram os aspectos revelados como fundamentais na vivência da família. A importância desses fatores está presente em todos os estudiosos do tema, pois não há como pensar em família sem considerar as relações interpessoais que ocorrem nesse contexto. Nesse sentido, Valente (2003) afirma que "família é fábrica de gente" (p.15), e os resultados parecem demonstrar que a qualidade da produção dessa fábrica é diretamente proporcional às características e estilos de cada um desses componentes da relação familiar.

Vale ressaltar que os elementos de cunho mais relacional e afetivo (tais como o diálogo, a afetividade, a comunhão, a cumplicidade, a escuta, a percepção das necessidades dos outros, a união, etc.) foram mais enfatizados pelas mulheres entrevistadas, coerentes com o papel da mulher enquanto cuidadora da casa e da família e responsável pela educação dos filhos. Por sua vez, o Sr. Adão, apesar de valorizar alguns desses fatores, prioriza os aspectos estruturais da família vinculados às funções masculinas de provisão e de relações com o mundo: moradia adequada/inadequada, desemprego, excesso de trabalho, dificuldades financeiras, importância das regras e dos limites, falta de condições de vida e arrimo, dentre outros.

Então, é aquela família que, assim, ninguém tá nem aí pra ninguém... um tá com dificuldade lá, tá envolvido com droga e tal, então "deixa ele pra lá, deixa ele viver a vida dele que eu não tô nem aí". A mãe falando isso, o pai, bebendo, não tá preocupado com isso... (T)

E a mãe e o pai, cada vez mais, pouco se preocupam... (Ad.)

As pessoas tomam as atitudes por si. É cada um assim, "Ah, eu vou fazer isso porque vai ser bom pra mim". Em nenhum momento, cê perguntou... "Você pediu opinião a sua mãe, cê procurou bater um papo com ela pra saber se é legal?", "Não tô nem aí pra minha mãe". É como se não tivesse... se fosse... é isso mesmo, é todo mundo largado. (T) 
No que concerne à vivência dos elementos desintegradores da família, a ênfase nos aspectos das relações familiares mais uma vez se faz presente. A falta de escuta, de diálogo, de cumplicidade, de comunhão e de união pode ser traduzida em um outro fato apontado como desestabilizador da família: o individualismo. Ele é descrito como a ausência de interesse nas questões que não lhe dizem respeito, mesmo se tratando de situações críticas. A falta de união, sendo esta última considerada fundamental para a vivência de família como suporte e apoio para seus componentes, é uma das conseqüências do individualismo.

Sarti (2002) vincula a individualidade (no mesmo sentido de individualismo) à perda do sentido da tradição. Assim, no mundo moderno, os papéis outrora préestabelecidos em relação ao casamento, à família, à sexualidade, ao amor e ao trabalho passam a ser construídos em uma perspectiva em que a individualidade ganha cada vez mais espaço. Com essa mudança de referência, os papéis familiares tradicionais passam a gerar conflitos, pois torna-se necessário compatibilizar o individual com a reciprocidade familiar. É evidente que essa situação se reflete, diretamente, na qualidade das relações estabelecidas no grupo domiciliar. Ao se referir ao segmento social menos favorecido economicamente, a autora afirma que a tradição constitui uma referência fundamental da existência. A condição de desigualdade e de exclusão em relação à sociedade mais ampla leva as famílias pobres a manter a lógica da reciprocidade (em oposição ao princípio da individualidade), manifestada nos laços de solidariedade, de parentesco e de vizinhança, tão necessários a sua sobrevivência.

A partir das considerações de Sarti e da análise fenomenológica dos depoimentos, uma reflexão mais atenta sobre o individualismo no grupo familiar mostra que ele está na contramão do fortalecimento das relações, inclusive as afetivas. A esfera do "entre", do inter-humano, fica esvaziada, e as pessoas deixam de ser consideradas, confirmadas e assistidas em sua singularidade, além de experimentarem um sentimento de solidão. Some-se a isso o fato de que o desprezo pela cultura e pelas tradições do seu grupo familiar promove o des-enraizamento de sua história, o qual, certamente, acarreta um senso de identidade pessoal frágil e desconectado das referências básicas, fundamentais para o desenvolvimento de uma auto-imagem positiva e forte. Nesse sentido, é possível supor que esse enfraquecimento da identidade (e, em conseqüência, da autoestima) pode estar na base de diversos casos de alcoolismo, depressão e de violências múltiplas, tão comuns nas comunidades populares e reveladas nessa pesquisa como outros fatores que desestruturam a família.

...Eu não sei se hoje o alcoolismo é causa ou
se é conseqüência. (Ad.).
...Porque a pessoa vai beber porque tá
desempregado. Então, o desemprego, a falta
de oportunidade, os adolescentes querem
trabalhar e não conseguem, isso eu acho
que isso são elementos que fazem isso
(desestruturar a família). (Ad.)

O Sr. Adão se reporta a outros fatores desintegradores do grupo familiar distintos daqueles vinculados à qualidade das relações familiares. Sua ênfase recai, novamente, sobre elementos mais vinculados à estruturação da família. Assim, falta de condições de vida, de oportunidades e de acesso à educação, moradia inadequada e excesso de trabalho são vivenciados como promotores do esfacelamento da dinâmica familiar. O trabalho pode se tornar um poderoso determinante do enfraquecimento do grupo familiar, seja pelo seu excesso, seja pelo desemprego ou pela falta de oportunidades. Implicitamente, esses fatores desintegradores referem-se à figura masculina, quer na função do marido desempregado e sem oportunidades, quer na do pai ausente 
pelo envolvimento demasiado com o trabalho. Tais fatores são vivenciados como essencialmente desestabilizadores, pois não há como considerar uma família estruturada em que o pai esteja desempregado ou na situação oposta, ausente pela falta de tempo em decorrência do excesso de atividades profissionais.

Esses aspectos são abordados por Sarti (2003b) na associação direta entre o valor do trabalho e a identidade masculina, especialmente nas populações mais pobres, pois é justamente por meio da sua competência e da disponibilidade para o trabalho que o homem deixa de ser "pobre" e se afirma como qualquer outro, independentemente da condição social e econômica. A honra também está intimamente ligada à vivência do trabalho, porque mostra a capacidade do homem de trazer o dinheiro para dentro de casa e de sustentar a família. Com isso, o desemprego passa a ter um outro sentido, além das conseqüências da privação material: o da humilhação, visto que o despoja de uma função primordial à sua identidade social, como trabalhador, provedor e pai de família. A autora conclui ainda que essa perda moral se reflete em todo o grupo familiar, por se tratar de um de seus eixos fundamentais.

...Sem condições de moradia, não dão conta, não estão dando conta. Então, tem muita família desestruturada. (Ad.)

...Por causa de morar numa vila que tem muitos problemas, principalmente de alcoolismo, de drogas, essas coisas e tudo tal ... sem pertencer ao caminho que não deve, que é esse caminho da droga, da perdição, da prostituição que a gente sempre vê. (Ap.)

A questão da moradia inadequada foi enfatizada pelo sr. Adão como um elemento desestabilizador da família. Por "moradia inadequada", entendem-se as construções realizadas de maneira improvisada (barracos) e frágil, com poucas divisões (algumas possuem apenas um único cômodo para abrigar toda a família), com espaços exíguos que não preservam nenhum tipo de intimidade (nem dentro da própria casa nem com as habitações do entorno), sem infra-estrutura (água encanada, esgoto, etc), com móveis insuficientes para a demanda familiar, muitas vezes situada em locais sujos, em que existem ratos e outros animais transmissores de doenças. Essa conjuntura expõe as famílias a circunstâncias de riscos e de vulnerabilidades de ordens diversas, com repercussões diretas no seu cotidiano, na sua auto-imagem e na integridade de cada um de seus membros. Associada a esse problema concreto da moradia, há, da mesma forma, a vivência de problemas vinculados ao ambiente externo, como a violência, a prostituição, a marginalidade e o envolvimento com o tráfico de drogas.

Saleh (2001) associa a questão da moradia à possibilidade de contribuir para uma identidade negativa ("ser favelado"), tanto por parte dos outros como no que tange à própria auto-imagem. Isso se dá pelo fato de a moradia estar vinculada ao grau de dignidade da pessoa. Assim, a moradia inadequada surge como uma preocupação presente e como um fator estressor comum no ciclo de vida das famílias por ela investigadas. Como formas de enfrentamento desenvolvidas pelas pessoas para reverter essa circunstância familiar, a autora ressalta a capacidade de manter a família unida, a subsistência material, a educação, a manutenção de respeito (especialmente dos filhos para com os pais) e a força obtida através da fé.

Nas comunidades populares, não há garantia de uma vida familiar tranqüila, pois existem muitos perigos, como os vizinhos. Trata-se de uma luta diária e de um stress constante, pois seus moradores, particularmente aqueles das favelas onde existe a presença do tráfico de drogas, do crime organizado ou das milícias, sabem do equilíbrio precário de sua vida cotidiana, mesmo nos momentos de aparente tranqüilidade. 


\begin{abstract}
...Nós fomos criados sem o pai, só com minha mãe. Aí, eu e meu irmão mais velho éramos os mais velhos. Eaí a gente tinha que dar conta dos pequenos... (Ad.)

A vida de infância foi tão corrida, eu tava trabalhando, trabalhando, trabalhando... Se o meu pai tivesse, eu não tinha que assumir as responsabilidades tão cedo. Eu tive que assumir as responsabilidades. (Ad.)
\end{abstract}

Outro componente da vivência familiar revelado na pesquisa é aquele que diz respeito ao trabalho na infância, particularmente expresso no depoimento da Sra. Aparecida e do Sr. Adão. Este iniciou precocemente dois tipos de atividades (por sinal, comuns entre as crianças das famílias de baixa renda, em maior ou menor grau): o serviço doméstico e a criação dos irmãos menores. Ele atribui essa situação, expressamente, à ausência do pai na família: a mãe saía para lavar roupas e, com isso, garantir o sustento financeiro da família, enquanto as tarefas domésticas e a criação dos irmãos menores ficavam a seu cargo e a cargo do irmão mais velho.

O desempenho dos serviços domésticos por parte das crianças não está, necessariamente, vinculado à ausência paterna. Desde cedo, as mães procuram ensinar aos filhos os afazeres básicos da rotina doméstica, seja porque elas, assim como os maridos, trabalham fora, seja "para eles já saberem, no caso de uma precisão" (Ap.).

Ainda no que concerne ao trabalho como fator de encurtamento da infância, Vasconcelos (1999) também verificou que é comum ele ocorrer de maneira diferente daquela exposta pelo Sr. Adão: como trabalho remunerado, sob a forma de biscates ou de pedidos de dinheiro às pessoas na rua. Infelizmente, sabe-se que essa situação é comum nas camadas populares, ao contrário do que deveria acontecer.

Finalmente, uma consideração que se faz necessária diz respeito à importância singular da música como elemento estruturante da vivência de família da Sra. Tânia. A forma apaixonada com que ela descreve a música, e as diversas expressões sobre o modo como envolve os familiares e dá um sentido à sua vida, não pode ser desprezada. Sua vivência da música como elemento que estrutura a família aponta a importância do envolvimento dos familiares em um projeto comum a todos, seja de cunho artístico, seja religioso, social ou cultural. Atividades dessa natureza proporcionam um sentido, facilitam a integração e promovem o exercício das habilidades necessárias ao relacionamento interpessoal de qualidade.

\section{Considerações finais}

Esta pesquisa, realizada com pessoas moradoras em uma comunidade popular, constituiu-se em um recorte mínimo de um campo extremamente amplo, por sua riqueza, diversidade e complexidade. Uma das suas contribuições foi a ênfase na compreensão fenomenológica da vivência de família. Conforme explicitada anteriormente, a vivência, no presente estudo, foi concebida como a repercussão, no indivíduo, das suas conexões com o mundo, enquanto ser ex-istente, que está-aí, antes de qualquer elaboração racional. Nesse aspecto, ela serve como uma referência fundamental que nos dá o sentido das coisas do mundo, de modo irrefletido, ou seja, anterior ao uso do intelecto, e sustenta o modo pelo qual nos posicionamos na vida.

Conclui-se que a compreensão das vivências é fundamentada na elaboração de estratégias de assistência às comunidades populares, pois ela nos revela "o que vem de dentro", o que é essencialmente fortalecedor e enfraquecedor nas relações entre as pessoas e o mundo. A compreensão das vivências acrescenta o viés singular daqueles a quem se quer beneficiar com qualquer proposta de amparo ou auxílio. 
Assim, por exemplo, de acordo com a ênfase dada aos aspectos referentes às relações familiares captadas nos depoimentos, ao se pretender desenvolver um projeto de assistência psicológica junto às famílias de comunidade popular, pode ser importante a oferta de um espaço no qual as pessoas possam desenvolver e exercitar as qualidades facilitadoras das relações interpessoais e da expressão dos afetos. É obvio que há uma demanda imensa por programas de complementação de renda e de geração de trabalho, como aqueles de capacitação profissional. Também são de grande valia para essa parcela da população as ofertas de serviços jurídicos e outros, de natureza cultural e esportiva, por exemplo. Entretanto, no que se refere à contribuição da Psicologia, o trabalho com grupos pode promover o desenvolvimento das habilidades sociais básicas dentro e fora da família, tais como a capacidade de se expressar, de ouvir a perspectiva alheia ou de dar feedback, dentre tantas outras.

Outra consideração decorrente deste estudo sobre a vivência de família referese à importância da adoção, por parte do psicólogo, de uma postura de valorização do potencial e das capacidades das pessoas mais simples, pois se, para qualquer pessoa, isso melhora a auto-imagem e, em conseqüência, a auto-estima, no caso dessas pessoas, há um diferencial. Por sua condição social e de moradia, muitas vezes são desqualificadas em seu saber e em seu potencial. Não se trata de um saber adquirido nas instituições de ensino, mas na escola da vida, que também as qualifica para o desenvolvimento pessoal. A importância de se contemplar o seu contexto, de reconhecer e de legitimar o seu conhecimento, a sua cultura e os seus valores intelectuais e espirituais, sem querer enquadrá-la nos moldes vigentes de família, de saúde e de cultura, confirma suas origens, reforça seu senso de pertencimento ao seu grupo de referência e, a partir daí, fortalece sua identidade.

Finalmente, a diversidade de elementos que compõem a vivência de família revelada nesta pesquisa inspira o desejo de aprofundá-los em pesquisas posteriores. Assim, um estudo fenomenológico sobre a importância da religião, ou das funções paterna e materna na vivência de família, aprofundaria os temas aqui apresentados e abriria novas perspectivas. Outra questão que também se faz presente é se uma pesquisa com objetivo semelhante ao desta, realizada com pessoas que pertencem a uma família menos estruturada do que aquelas das participantes deste estudo, apresentaria unidades de significado semelhantes às captadas nesta investigação. Outra possibilidade seria pesquisar especificamente os elementos que desestruturam a vivência de família e seus desdobramentos na vida pessoal. Considerando-se que a ênfase dos entrevistados foi sobre a díade pai/ mãe, pesquisar a vivência do casamento, nesse contexto, também seria de extrema importância.

Enfim, a presente pesquisa, longe de esgotar o assunto que pretendeu investigar, abre diversas possibilidades de aprofundamento e de investigação acerca dos elementos fundamentais da vivência de família das comunidades populares. Assim, as considerações aqui apresentadas são finais em relação a esse trabalho, mas, definitivamente, estão longe de serem conclusivas. 


\section{Claudia Lins Cardoso*}

Doutora em Psicologia Clínica pela PUC-Rio. Professora adjunta do Departamento de Psicologia da Faculdade de Filosofia e Ciências Humanas - Universidade Federal de Minas Gerais, Belo Horizonte, MG - Brasil.

\section{Terezinha Féres-Carneiro}

Doutora em Psicologia Clínica pela PUC/SP, Pós-Doutorado em Terapia de Família e Casal pela Universidade de Paris 5, Sorbonne, pesquisadora $1 \mathrm{~A}$ do CNPq. Professora titular do Departamento de Psicologia da Pontifícia Universidade Católica do Rio de Janeiro, Rio de Janeiro, RJ - Brasil.

\section{José Paulo Giovanetti}

Doutor em Psicologia pela Universidade Católica de Louvain, Bélgica. Professor titular da Faculdade dos Jesuítas, professor titular da FEAD-Minas, Belo Horizonte, MG - Brasil.

\section{*Endereço para envio de correspondência:}

Rua Alagoas, 1314/516 - Belo Horizonte - MG - Brasil - CEP: 30130-160

E-mail: clins.bh@terra.com.br

Recebido 02/10/2008, Aprovado 11/04/2009

Amatuzzi, M. M. (1996). Apontamentos acerca da pesquisa fenomenológica. Estudos de Psicologia, 13(1), 5-10.

Amatuzzi, M. M. (2001a). Por uma psicologia humana. Campinas, SP: Alínea.

Amatuzzi, M. M. (2001b). Pesquisa fenomenológica em psicologia. In A. F. Holanda \& M. A. T. Bruns, Psicologia e pesquisa fenomenológica: reflexões e perspectivas. São Paulo: Ômega.

Cardoso, C. L., \& Féres-Carneiro, T. F. (2008, 1ํ semestre). Sobre a família: com a palavra, a comunidade. Estudos e Pesquisas em Psicologia, 8(2) 511-526.

Forghieri, Y. C. (1993). Psicologia fenomenológica: fundamentos, método e pesquisa. São Paulo: Pioneira.

Giorgi, A. (1985). Phenomenology and psychological research. Pittsburg: Duquesne University Press.

Gomes, H. S. R. (1988). Um estudo sobre o significado de família. Tese de Doutorado, Pontifícia Universidade Católica de São Paulo, São Paulo.

Mello, S. L. (2002). Família: perspectiva teórica e observação factual. In M. C. B. Carvalho (Org.), A família contemporânea em debate. São Paulo: EDUC/Cortez.

Moreira, D. A. (2002). O método fenomenológico na pesquisa. São Paulo: Pioneira Thomson.

Oliveira, Z. L. C. (2005). A provisão da família e a pobreza: o caso de Belo Horizonte. In Seminário: as famílias e as políticas públicas. Belo Horizonte: Abep. Recuperado em 01 de agosto de 2007, de http://www.abep nepo.unicamp.br/docs/anais/outros/FamPolPublicas/ ZuleicaOliveira.pdf

Oliveira, M. L. S., \& Bastos, A. C. S. (2000). Práticas de atenção à saúde no contexto familiar: um estudo comparativo de casos. Psicologia: Reflexão e Crítica, 13(1), 97-107.
Disponível em:http://www.abep.nepo.unicamp.br/docs/ anais/outros/FamPolPublicas/ZuleicaOliveira.pd

Saleh, L. P. (2001). Famílias em contexto de pobreza: preocupações e necessidades. Dissertação de Mestrado em Psicologia Clínica, Pontifícia Universidade Católica de São Paulo, São Paulo.

Sarti, C. (2002). Família e individualidade: um problema moderno. In M. C. B. Carvalho (Org.), A família contemporânea em debate. São Paulo: EDUC/Cortez.

Sarti, C. (2003a). Famílias enredadas. In A. R. Acosta \& M. A. F. Vitale (Orgs.), Família: rede, laços e políticas públicas. São Paulo: IEE- Puc-SP.

Sarti, C. (2003b). A família como espelho: um estudo sobre a moral dos pobres (2a ed. rev.). São Paulo: Cortez.

Silveira, T. M. (2007). Por que eu? A doença e a escolha do cuidador familiar. Rio de Janeiro: Archimedes.

Szymanski, H. (2002). Teorias e "teorias" de famílias. In M. C. B. Carvalho (Org.), A família contemporânea em debate. São Paulo: EDUC/Cortez.

Thiollent, M. (2000). Metodologia da pesquisa-ação (10a ed.). São Paulo: Cortez.

Valente, C. (2004). Um olhar sobre a família: trajetória e desafios de uma ONG. São Paulo: Agora.

Valle, E. (1998). Psicologia e experiência religiosa: estudos introdutórios. São Paulo: Loyola.

Vasconcelos, E. M. (1999). Educação popular e atenção à saúde da família. São Paulo: Hucitec.

Vaz, H. C. L. (1986). Escritos filosóficos: problemas de fronteira. São Paulo: Loyola, 1986. 